\title{
Functional lateralization of the medial prefrontal cortex in the modulation of anxiety in mice: Left or right?
}

\author{
N.S. Costa ${ }^{\text {a, c }}$, M.A. Vicente ${ }^{\text {a }}$, A.C. Cipriano ${ }^{\text {a, c }}$, T.T. Miguel ${ }^{\text {a, b }}$, R.L. Nunes-de-Souza ${ }^{\text {a, c, * }}$ \\ a Lab. Pharmacology, School of Pharmaceutical Sciences, Univ. Estadual Paulista, UNESP, Araraquara, SP, 14801-902, Brazil \\ ${ }^{\mathrm{b}}$ Institute of Biomedical Sciences, Federal University of Uberlândia (UFU), Uberlândia, MG, Brazil \\ ${ }^{\mathrm{c}}$ Joint UFSCar-UNESP Graduate Program in Physiological Sciences, Araraquara, SP, Brazil
}

\section{A R T I C L E I N F O}

\section{Article history:}

Received 18 December 2015

Received in revised form

4 April 2016

Accepted 10 April 2016

Available online 11 April 2016

\section{Keywords:}

Anxiety

Functional lateralization

Mice

mPFC

Stress

\begin{abstract}
A B S T R A C T
It has been suggested that the left medial prefrontal cortex (LmPFC) has an inhibitory role in controlling the right $\mathrm{MPFC}(\mathrm{RmPFC})$, thereby reducing the deleterious effects of stressors on emotional states. Here, we investigated the effects on anxiety of bilateral or unilateral injections of NOC-9 [a nitric oxide (NO) donor] and cobalt chloride $\left(\mathrm{CoCl}_{2}\right.$; a synaptic inhibitor) into the mPFC of mice exposed to the elevated plus-maze (Experiments 1 and 2). The effects of restraint or social defeat on anxiety in undrugged mice were recorded at $5 \mathrm{~min}$ or $24 \mathrm{~h}$ after exposure to the stress (Experiment 3). Experiment 4 investigated the effects of LmPFC injection of $\mathrm{CoCl}_{2}$ combined with restraint or social defeat on anxiety, which was recorded $24 \mathrm{~h}$ later. Although intra-RmPFC NOC-9 produced anxiogenesis, its injection into the LmPFC, or bilaterally, did not change anxiety. Intra-RmPFC or - $\mathrm{LmPFC}$ injection of $\mathrm{CoCl}_{2}$ produced anxiolytic- and anxiogenic-like effects, respectively. Both restraint and social defeat produced anxiogenesis at $5 \mathrm{~min}$, but defeated mice did not display anxiety $24 \mathrm{~h}$ after the stress. Although intra-LmPFC $\mathrm{CoCl}_{2}$ did not change anxiety, which was recorded $24 \mathrm{~h}$ later in non-stressed mice, this synaptic inhibitor produced a clear, anxiogenic-like effect in defeated (but not restrained) mice. These results suggest that (i) nitrergic activation of the RmPFC increases anxiety, which in turn is inhibited by NO production within the LmPFC; (ii) neuronal inhibition of the RmPFC or LmPFC elicits anxiolysis and anxiogenesis, respectively; and (iii) inactivation of the LmPFC results in recrudescence of anxiety induced by social defeat stress.
\end{abstract}

(C) 2016 Elsevier Ltd. All rights reserved.

\section{Introduction}

Dysfunctions of the medial prefrontal cortex ( $\mathrm{MPFC}$ ) have long being related to psychiatric disorders, such as depression and anxiety. This limbic area is involved in memory (Euston et al., 2012), decision-making (Bechara and Damasio, 2002), cognitive flexibility (Gruber et al., 2010), executive cognition (Yuan and Raz, 2014), social interaction and emotional processing (Damasio, 2000). The mPFC shows dense reciprocal connections with other areas [e.g., amygdala, hippocampus, hypothalamus, dorsal raphe, and midbrain periaqueductal gray (e.g., Euston et al., 2012)], which facilitates its ability to modulate fear and anxiety states (Courtin et al., 2013; Gold et al., 2015). Previous studies have shown that a lesion of the mPFC decreases anxiety-related behavior in rats

\footnotetext{
* Corresponding author. Lab. Farmacologia, Faculdade de Ciências Farmacêuticas, UNESP, Rodovia Araraquara-Jaú, Km 01, 14800-903 Araraquara, SP, Brazil.

E-mail addresses: souzarn@fcfar.unesp.br, ricardo.souza@pq.cnpq.br (R.L. Nunes-de-Souza).
}

exposed to the elevated plus maze (EPM) (Gonzalez et al., 2000; Lacroix et al., 2000; Shah and Treite, 2003) and increases social interaction (Gonzalez et al., 2000; Shah and Treite, 2003). These results have emphasized the importance of the $\mathrm{MPFC}$ as a potential target for the effects of anti-anxiety drugs (e.g., McNaughton and Corr, 2004; Jaferi and Bhatnagar, 2007; Holmes and Wellman, 2009).

It has been reported that hemispheric lateralization of the PFC is involved in the control of emotional processing in humans (Davidson, 1998). Studies have shown that the mPFC has a lateralized role in the modulation of neuroendocrine and autonomic responses to stress in various mammals. For instance, right or bilateral (but not left) lesions of the MPFC reduce the corticosterone peak induced by restraint stress in rats (Sullivan and Gratton, 1999). In addition, chronic stress situations have been related to volumetric and functional alterations of the MPFC, which appears to be lateralized, with hyperactivation of the right MPFC and decreased left mPFC activity (Cerqueira et al., 2008; Davidson, 1998; Johnstone et al., 2007). Moreover, the left mPFC has inhibitory control over the 
right $\mathrm{mPFC}$ under basal conditions. According to Cerqueira et al. (2007), dysfunction of the mPFC can be related to the loss of resilience, thereby contributing to the triggering of maladaptive responses. This finding suggests that understanding the underlying mechanisms of these mPFC hemispheric specializations would be useful for understanding how other potential treatments function (e.g., repetitive transcranial magnetic stimulation over left or right frontal cortex).

Several neurotransmitters (e.g., monoamines, GABA, glutamate, and endocannabinoids) are involved in the modulation of anxietyrelated responses (e.g., Carobrez et al., 2001; Fogaça et al., 2012; Molchanov and Guimarães, 2002; Vianna et al., 2001). Additionally, the atypical neurotransmitter nitric oxide (NO) has been shown to be an important pro-aversive gas in areas of the brain defense system (for a review, see Guimarães et al., 2005). NO is produced by the nitric oxide synthase (NOS) enzyme, through the conversion of $\mathrm{L}-$ arginine to L-citrulline, using nicotinamide adenine dinucleotide phosphate (NADPH) and $\mathrm{Ca}^{2+}$ as co-factors (Mayer et al., 1991; Lohse et al., 1998). Sympathetic ("fight or flight") reactions have been demonstrated after injection of NO donors [e.g., SIN-1 (3morpholino-sylnomine hydrochloride) and NOC-9 (6-(2-Hydroxy1-methyl-2-nitrosohydrazino)- $N$-methyl-1-hexanamine)] into the midbrain periaqueductal gray (PAG) in rats (Guimarães et al., 2005) and mice (Miguel et al., 2012) and into the bed nucleus of the stria terminalis (BNST) in mice (Faria et al., 2016). Unlike SIN-1, which produces peroxynitrite, thereby provoking cytotoxic effects and causing other NO-independent cellular effects (Del Carlo and Loeser, 2002; Morot Gaudry-Talarmain et al., 1997), NOC-9 is relatively stable at an alkaline $\mathrm{pH}(>10.0)$ and produces $\mathrm{NO}$ at a physiological $\mathrm{pH}$ (7.4), without producing peroxynitrite (Ambalavanan et al., 1999; Del Carlo and Loeser, 2002; Seccia et al., 1996).

In addition to nitrergic activation, electrolytic and chemical lesions have been extensively used to investigate the role of a brain area in the modulation of emotional responses. However, many of these procedures produce more permanent damage to a structure. To avoid this problem, several studies have used cobalt chloride $\left(\mathrm{CoCl}_{2}\right)$ as a chemical tool to investigate the role of a selected brain structure in the modulation of various emotional responses (e.g., Crestani et al., 2009, 2010; Scopinho et al., 2010; Tavares and Corrêa, 2006). $\mathrm{CoCl}_{2}$ reduces presynaptic calcium influx by competing with this bivalent cation, thereby inhibiting reversible neurotransmitter release (Kretz, 1984). The duration of action of $\mathrm{CoCl}_{2}$ is relatively short (approximately 30-60 min) and this synaptic inhibitor does not alter the function of the fibers of passage (Lomber, 1999), which results in a more accurate evaluation of a specific brain structure function.

Thus, using intracerebral injections of NOC-9 or $\mathrm{CoCl}_{2}$, the present study investigated the role of the $\mathrm{MPFC}$ in anxiety in mice exposed to the EPM. The effects of nitrergic activation of the mPFC were observed after unilateral (into the right or left $\mathrm{MPFC}$ ) and bilateral injections of the NO donor (experiment one). In experiment two, we investigated whether the right or left MPFC inhibition would change the basal levels of anxiety. Then, in experiment three, the influence of the two types of stressors (restraint and social defeat) on anxiety was evaluated at $5 \mathrm{~min}$ or $24 \mathrm{~h}$ after stress exposure. Finally, the effect of restraint or social defeat stress, in combination with left mPFC inhibition, on anxiety was investigated at $24 \mathrm{~h}$ in mice exposed to the EPM (experiment four).

\section{Materials and methods}

\subsection{Subjects}

Two hundred and fifty one male Swiss mice (Univ. Estadual Paulista - UNESP, SP, Brazil) weighing 25-35 g at testing were used in this study. Mice were housed in groups of 10 per cage (size: $41 \times 34 \times 16 \mathrm{~cm}$ ) and maintained under a normal 12-h light cycle (lights on at 7:00 a.m.) in a temperature-controlled environment $\left(23 \pm 2{ }^{\circ} \mathrm{C}\right)$. Food and water were freely available except during the brief test periods. All mice were naive at the beginning of the experiments and they were used once. Housing conditions and experimental procedures were approved by the Ethical Committee for Use of Animals of the School of Pharmaceutical Science/UNESP, which complies with Brazilian and international guidelines for animal use and welfare.

\subsection{Drugs}

The following drugs were used: Cobalt chloride $\left(\mathrm{CoCl}_{2}-\right.$ nonspecific synaptic blocker - $1.0 \mathrm{mM} / 0.2 \mu \mathrm{L}$-dissolved in $0.9 \%$ physiological saline solution); NOC-9 [6-(2-hydroxy-1-methyl-2nitrosohydrasino)- $N$-methyl-1-hexanamine - NO donor - 9.37, $18.75,37.5$ or $75 \mathrm{nmol} / 0.2 \mu \mathrm{L}$ - dissolved in vehicle ( $1 \mathrm{M}$ Tris- $\mathrm{HCl}$ solution, $\mathrm{pH} 10$ ), to prevent NO release before it reaches brain tissue]. Doses were based on previous studies (Miguel et al., 2012; Resstel et al., 2004).

\subsection{Surgery and microinjection}

Each mouse was bilateral or unilaterally implanted with a $7 \mathrm{~mm}$ stainless steel guide cannulae (26 gauge; Insight Equipamentos Científicos Ltd., Brazil) into the MPFC under anesthesia induced by intraperitoneal injection of ketamine $(100 \mathrm{mg} / \mathrm{kg}$ ) plus xylasin (10 $\mathrm{mg} / \mathrm{kg}$ ). Guide cannulae were fixed to the skull with dental acrylic and jeweler's screws. Stereotaxic coordinates (Paxinos and Franklin, 2001) for the mPFC were, respectively, $1.7 \mathrm{~mm}$ anterior to bregma, + and/or $-0.3 \mathrm{~mm}$ lateral to the midline for left and right hemispheres, respectively, and $2.1 \mathrm{~mm}$ ventral to the skull surface, with the guide cannulae in the vertical position. A dummy cannula (33 gauge, stainless steel wire; Fishtex Industry and Commerce of Plastics Ltd.), inserted into each guide cannula, served to reduce the incidence of occlusion. Immediately after surgery, the animals received an intramuscular injection of penicillin- $G$ benzathine (Pentabiotic, $56.7 \mathrm{mg} / \mathrm{kg}$ in a $0.1 \mathrm{~mL}$ volume; Fort Dodge, Campinas, SP, Brazil) and a subcutaneous injection of the antiinflammatory analgesic Banamine $(3.5 \mathrm{mg} / \mathrm{kg}$ flunixin meglumine, Intervet Schering-Plough, Rio de Janeiro, RJ, Brazil, in a volume of $0.3 \mathrm{~mL}$ ). Five to seven days after surgery, solutions (see Drugs section) were injected into the mPFC through microinjection units (33 gauge stainless steel cannula; Insight Equipamentos Científicos Ltda., Brazil), which extended $1.0 \mathrm{~mm}$ beyond the tip of the guide cannula. Each microinjection unit was attached to a $2 \mu \mathrm{L}$ Hamilton microsyringe via polyethylene tubing (PE-10). The microinjection procedure consisted of gently restraining the animal, removing the dummy cannula, inserting the injection unit in situ and proceeding with the microinjection over a 30-s period, after which the needle was left for a further $30 \mathrm{~s}$. The final volume delivered was $0.2 \mu \mathrm{L}$. The successful procedure was verified by monitoring the movement of a small air bubble in the PE-10 tubing.

\subsection{Elevated plus maze and behavioral analysis}

The basic elevated plus maze (EPM) design comprised two open arms $(30 \times 5 \times 0.25 \mathrm{~cm})$ and two closed arms $(30 \times 5 \times 15 \mathrm{~cm})$, connected via a common central platform $(5 \times 5 \mathrm{~cm})$. The apparatus was constructed from wood (floor) and transparent glass (clear walls) and was raised to a height of $38.5 \mathrm{~cm}$ above floor level. After drug injection (see Experiments 1, 2 and 4 for details) into the $\mathrm{mPFC}$, each mouse was placed in an individual holding cage and then transported to the maze. Testing commenced by placing the 
subject on the central platform of the maze (facing an open arm), following which the experimenter immediately withdrew to an adjacent room. The test sessions were $5 \mathrm{~min}$ in duration and, between subjects, the maze was thoroughly cleaned with $20 \%$ alcohol. All experiments were performed under normal laboratory illumination $(1 \times 60 \mathrm{~W}$ yellow incandescent lamp positioned approximately $1.80 \mathrm{~m}$ above the EPM floor), during the light phase of the light-dark cycle. All sessions were recorded by a vertically mounted camera linked to a monitor and DVD recorder. Test DVDs were scored using the software "X-plo-rat 2005", developed by Dr. Morato's group at Faculdade de Filosofia, Ciências e Letras, USP at Ribeirão Preto, Brazil (the software can be freely downloaded at http://scotty.ffclrp.usp.br/X-Plo-Rat.html). Behavioral parameters comprised conventional spatiotemporal measures: frequencies of open and closed-arm entries (CE: entry = all four paws into an arm) and the time spent in the open arm of the maze. These data were used to calculate percentage of open-arm entries [(\%OE) - (open/ total) $\times 100$ ] and percentage of time (\%OT) (Rodgers and Johnson, 1995).

\subsection{General procedure}

\subsubsection{Experiment 1: effects on behavior of NOC-9 injected bi- or} unilaterally (the right or left) into the MPFC of mice exposed to the EPM

Five to seven days after surgery, mice were transported to the experimental room and left undisturbed for at least $30 \mathrm{~min}$ prior to testing. Vehicle $(n=14)$ or NOC-9 were injected into the right [9.37 $(\mathrm{n}=11), 18.75(\mathrm{n}=10)$, or $37.5(\mathrm{n}=8) \mathrm{nmol} / 0.2 \mu \mathrm{L}$; Experiment $1 \mathrm{~A}]$, bilaterally [vehicle $(\mathrm{n}=11), 37.5(\mathrm{n}=8)$ or $75(\mathrm{n}=9) \mathrm{nmol} / 0.2 \mu \mathrm{L}$; Experiment $1 \mathrm{~B}$ ] or left [vehicle $(\mathrm{n}=12), 37.5(\mathrm{n}=9)$ or $75(\mathrm{n}=10)$ $\mathrm{nmol} / 0.2 \mu \mathrm{L}$; Experiment $1 \mathrm{C}$ ] $\mathrm{mPFC}$ and, 5 min later, each animal was placed on the EPM to record the anxiety indices (\%OE and \%OT) and locomotion (CE) for a 5-min period.

\subsubsection{Experiment 2: effects of $\mathrm{CoCl}_{2}$ injected into the RmPFC or LmPFC on behavior of mice exposed to the EPM}

Five to seven days after surgery, mice were transported to the experimental room and left undisturbed for at least $30 \mathrm{~min}$ prior to testing. Then, saline or $\mathrm{CoCl}_{2}(1 \mathrm{mM}, 0.2 \mu \mathrm{L})$ were injected into the LmPFC[Experiment 2A (saline: $\mathrm{n}=10 ; \mathrm{CoCl}_{2}: \mathrm{n}=11$ )] or RmPFC [Experiment 2B (saline: $\mathrm{n}=12 ; \mathrm{CoCl}_{2}: \mathrm{n}=12$ )] and, 10 min later, each mouse was exposed to the EPM to record the anxiety indices (\%OE and \%OT) and locomotion (CE) for a 5-min period.

\subsubsection{Experiment 3: effects of restraint or social defeat on anxiety in mice exposed to the EPM at $5 \mathrm{~min}$ or $24 \mathrm{~h}$ after stress}

Restraint stress consisted of placing a mouse in a plastic cylindrical restraining tube $(2.8 \mathrm{~cm}$ inner diameter and $11.5 \mathrm{~cm}$ long $)$ for a single 30-min period. Then, animals were returned to their home cages for a 5 -min $(n=10)$ or $24-h(n=9)$ period. During social defeat stress, mice (intruders) were individually placed into the home cage of an aggressive and dominant conspecific mouse (resident), which had previously been socially isolated for at least four weeks. The experimenter interrupted the resident mouse's attacks against the intruder mouse when the intruder mouse displayed a submissive posture [i.e., defensive upright posture: elevation of the body on its hind legs, front legs extended toward the aggressor, retracted head and arched ears (Miczek, 1982)] for at least $3 \mathrm{~s}$. After that, each mouse was returned to its home cage for a 5 -min $(\mathrm{n}=12)$ or $24-\mathrm{h}(\mathrm{n}=12)$ period. Both restrained and defeated mice were then individually exposed to the EPM. Then, anxiety indices (\%OE and \%OT) and locomotion (CE) were recorded during a 5-min test. Control groups included mice exposed to a familiar, non-aggressive mouse for a 5 -min period before being returned to their home cages. These groups were exposed to the EPM at $5 \min (n=12)$ or $24 \mathrm{~h}(\mathrm{n}=13)$ after the non-aggressive interaction.

\subsubsection{Experiment 4: effects of combined intra-LmPFC injection of $\mathrm{CoCl}_{2}$ and restraint or social defeat stress on anxiety-related behavior assessed $24 \mathrm{~h}$ later in mice exposed to the EPM}

Ten minutes after microinjection of saline or $\mathrm{CoCl}_{2}(0.2 \mu \mathrm{L})$ into the LmPFC, mice were subjected to restraint (saline: $\mathrm{n}=13 ; \mathrm{CoCl}_{2}$ : $\mathrm{n}=7$ ) or social defeat (saline: $\mathrm{n}=12 ; \mathrm{CoCl}_{2}: \mathrm{n}=14$ ) stress, as described above (see experiment three). Then, animals were returned to their home cages and, $24 \mathrm{~h}$ later, each mouse was placed on the EPM to record anxiety indices (\%OE and \%OT) and locomotion (CE) for a 5-min period. Control groups also received saline $(\mathrm{n}=10)$ or $\mathrm{CoCl}_{2}(\mathrm{n}=11)$ in the LmPFC, but were exposed to a familiar, non-aggressive mouse for a 5 -min period before being returned to their home cages for a 24 -h period and exposure to the EPM.

\subsection{Histological analysis}

At the end of testing, all animals received an intra-mPFC infusion of $0.2 \mu \mathrm{L}$ of $1 \%$ Evans blue using the same microinjection procedure as for the drugs. Animals were then sacrificed in a $\mathrm{CO}_{2}$ chamber, their brains were removed, and the injection sites were viewed histologically by referencing the Atlas of Paxinos and Franklin (2001). Microinjections were considered valid when the injection units reached the pre-limbic or the $\operatorname{Cg} 1$ portions of the mPFC. Data from animals with injection sites outside these dorsal portions of the mPFC were excluded from the study.

\subsection{Statistical analysis}

All results were initially subjected to Levene's test for homogeneity of variance. Where Levene's test indicated significant heterogeneity, results were transformed to their log and then confirmed for homogeneity of variance before being subjected to Student $t$-test for independent samples (Experiment 2), one- (Experiments $1 \mathrm{~A}-\mathrm{C}$ ) or two-way [Experiments 3 (factor 1: stress; factor 2: time) and 4 (factor 1: treatment; factor 2: stress condition)] analysis of variance (ANOVA) followed the post hoc Duncan test. In all cases, a difference with a $\mathrm{p}$ value $\leq 0.05$ was accepted as significant. In Figs. 2-5 (see Results section), bars represent means ( \pm SEM).

\section{Results}

\subsection{Injections into the $m P F C$}

Fig. 1 shows a schematic diagram (left) and a representative photomicrograph (right) of the micro-infusion sites within the mPFC of the mouse (Paxinos and Franklin, 2001). Although the mPFC is subdivided into cingulate $(\mathrm{Cg} 1)$, prelimbic (PrL) and infralimbic (IL) portions (Paxinos and Franklin, 2001), in the present study, the injection sites were positively confirmed in the dorsal portion of the mPFC ( $\mathrm{Cg} 1$ and $\mathrm{PrL})$.

\subsection{Experiments $1 A-C$ : nitrergic facilitation of the $M P F C$}

\subsubsection{Experiment 1A: anxiogenic-like effects of NOC-9 injected into the RmPFC}

Fig. 2A shows the effects of intra-RmPFC injections of NOC-9 (0, $9.37,18.75$ or $37.5 \mathrm{nmol}$ ) on frequency of closed-arm entries (upper panel) and anxiety-like indices (lower panel) of mice exposed to the EPM for a 5-min period. One-way ANOVA followed by Duncan's 


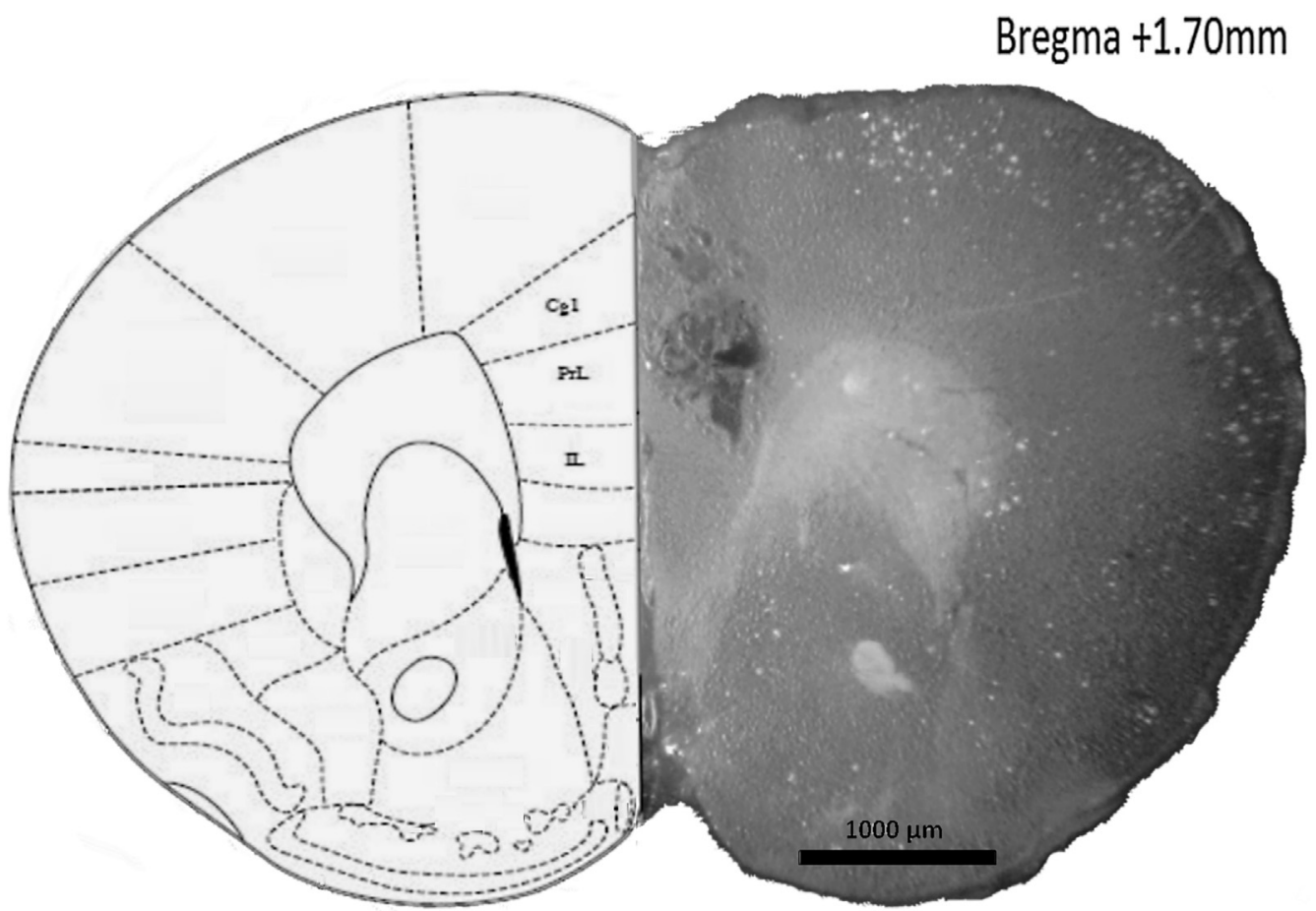

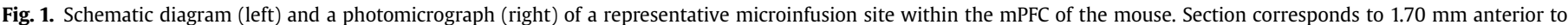
bregma (Paxinos and Franklin, 2001). Abbreviations: Cg1, cingulate cortex, area 1; IL, infralimbic cortex; PrL, prelimbic cortex.

test revealed that NOC-9 (all doses) decreased the \%OT $[\mathrm{F}(3,39)=3.25 ; \mathrm{p}<0.05]$. NOC-9 $(37.5 \mathrm{nmol})$ also reduced \%OE $[F(3,39)=2.91 ; p<0.05]$. Nitrergic activation of the RmPFC did not change the frequency of closed-arm entries $[\mathrm{F}(3.39)=0.41$; $\mathrm{p}>0.05]$.

\subsubsection{Experiment $1 B$ : No effects on anxiety of bilateral NOC-9} injection into the $\mathrm{mPFC}$

Through bilateral injections of NOC-9 in the MPFC, we hypothesized a more robust, anxiogenic-like effect. However, bilateral injections of this NO donor in the MPFC did not change the anxiety of mice exposed to the EPM. One-way ANOVA failed to show significant effects of bilateral injection of NOC-9 $(0,37.5$ or $75 \mathrm{nmol})$ into the $\mathrm{mPFC}$ on anxiety indices [\%OE: $\mathrm{F}(2,25)=0.26 ; \mathrm{p}=0.76$; \% OT: $\mathrm{F}(2,25)=0.20 ; \mathrm{p}=0.81]$ or general locomotor activity [CE: $\mathrm{F}(2,25)=0.40 ; \mathrm{p}=0.67$ ] in mice exposed to the EPM (Fig. 2B).

\subsubsection{Experiment 1C: No effects on anxiety of NOC-9 injected into} the LmPFC

The hypothesis that NO release exclusively in the LmPFC might reduce (rather than increase) anxiety was tested through NOC-9 injection into the LmPFC. Fig. $2 \mathrm{C}$ shows that intra-LmPFC
A

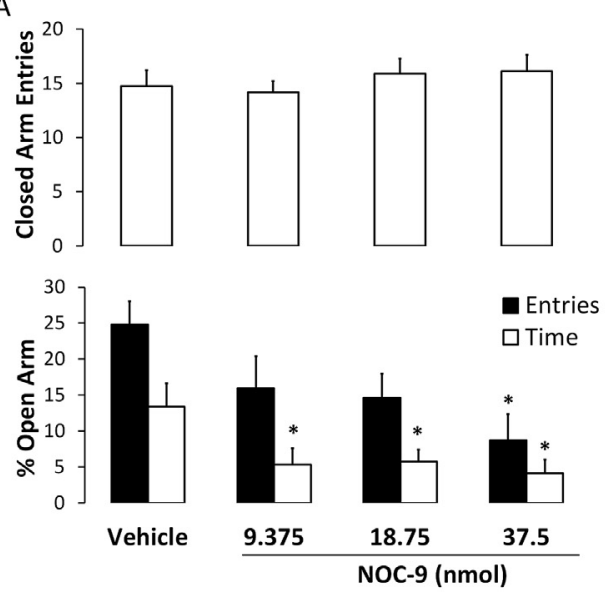

Surgery $\stackrel{5-7 \text { days }}{\longrightarrow}$ Microinjection $\stackrel{5 \text { min }}{\longrightarrow} \begin{gathered}\text { EPM } \\ (5 \mathrm{~min})\end{gathered}$

B
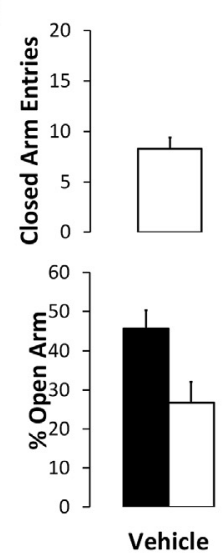
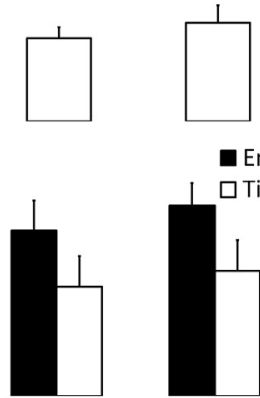

37.5
C
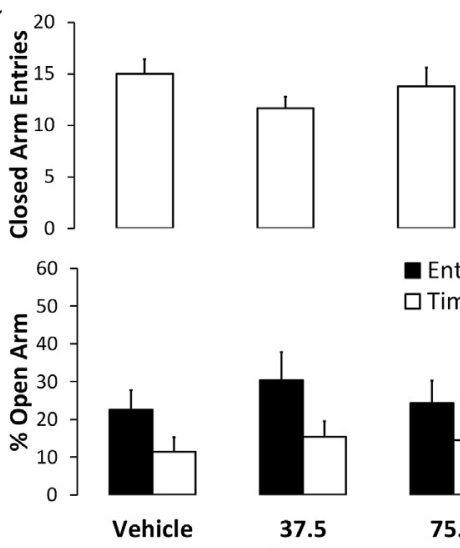

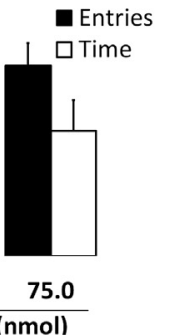

- Entries 口Time

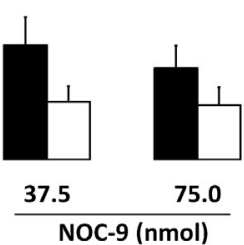

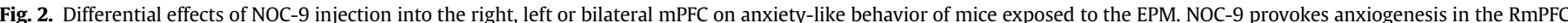

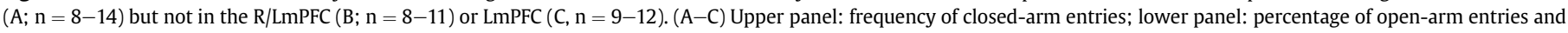
percentage of open-arm time. ${ }^{*} \mathrm{p}<0.05$ in comparison to vehicle group. 
injections of NOC-9 $(0,37.5$ or $75 \mathrm{nmol})$ did not change anxiety indices [\%OE: $\mathrm{F}(2,28)=1.12 ; \mathrm{p}=0.34 ; \% \mathrm{OT}: \mathrm{F}(2,28)=0.21$; $\mathrm{p}=0.80]$ or general locomotor activity [CE: $\mathrm{F}(2,28)=0.94$; $\mathrm{p}=0.40]$ in mice exposed to the EPM.

\subsection{Experiment 2: anxiogenic- and anxiolytic-like effects produced} by injection of $\mathrm{CoCl}_{2}$ into the LmPFC and the RmPFC, respectively

Fig. 3 shows the effects of $\mathrm{CoCl}_{2}$ (0 or $1 \mathrm{mM}$ ) injection into the LmPFC (A) or RmPFC (B) on the behavior of mice exposed to the EPM. Student's $t$-test revealed that mice that received injections of $\mathrm{CoCl}_{2}$ into the LmPFC explored the open arms less extensively than did saline-treated animals [\%OE $\left(t_{(32)}=2.34 ; \mathrm{p}<0.05\right)$ and \%OT $\left.\left(t_{(32)}=2.35 ; \mathrm{p}<0.05\right)\right]$. $\mathrm{CoCl}_{2}$ did not change the frequency of closed-arm entries (CE: $\left.t_{(32)}=0.36 ; \mathrm{p}>0.05\right)$ (Fig. 3A). Regarding the RmPFC, Student's $t$-test revealed that mice treated with $\mathrm{CoCl}_{2}$ explored the open arms more extensively than did saline-treated animals [\%OE $(\mathrm{t}(32)=3.36 ; \mathrm{p}=0.002)$ and \%OT $(\mathrm{t}(32)=2.30$; $\mathrm{p}=0.03)$ ]. Student's t-test did not reveal a significant effect of $\mathrm{CoCl}_{2}$ on the frequency of closed-arm entries (CE: $t(32)=0.26 ; \mathrm{p}>0.05)$ (Fig. 3B).

\subsection{Experiment 3: short-lasting anxiogenic-like effects induced by restraint or social defeat stress}

The immediate (5 min) and late ( $24 \mathrm{~h}$ ) effects of restraint or social defeat stress on the behavior of mice exposed to the EPM are shown in Fig. 4. Two-way ANOVA revealed an effect of the stress factor $[\mathrm{F}(2,62)=4.27 ; \mathrm{p}<0.02]$, the time factor $[F(1,62)=5.96 ; p<0.02]$ and of the stress $\times$ time interaction $[F(2,62)=3.07 ; p=0.05]$ on percentage of open-arm entries. Regarding the percentage of open-arm time, a two-way ANOVA revealed a significant effect of the time factor $[F(1,62)=4.97$; $\mathrm{p}<0.03]$ and borderline effects of the stress factor $[\mathrm{F}(2,62)=2.44$; $\mathrm{p}=0.09]$ and of the stress $\times$ time interaction $[\mathrm{F}(2,62)=2.71$; $\mathrm{p}=0.07]$. Duncan post hoc test revealed that social defeat reduced both \%OE and \%OT ( $\mathrm{p} \leq 0.05)$ when exposed to the EPM at $5 \mathrm{~min}$ after stress, whereas restraint stress significantly decreased only \% OE ( $p<0.05$ ). However, only restraint was able to reduce percentage of open-arm entries at $24 \mathrm{~h}$ after stress $(\mathrm{p}<0.05)$.

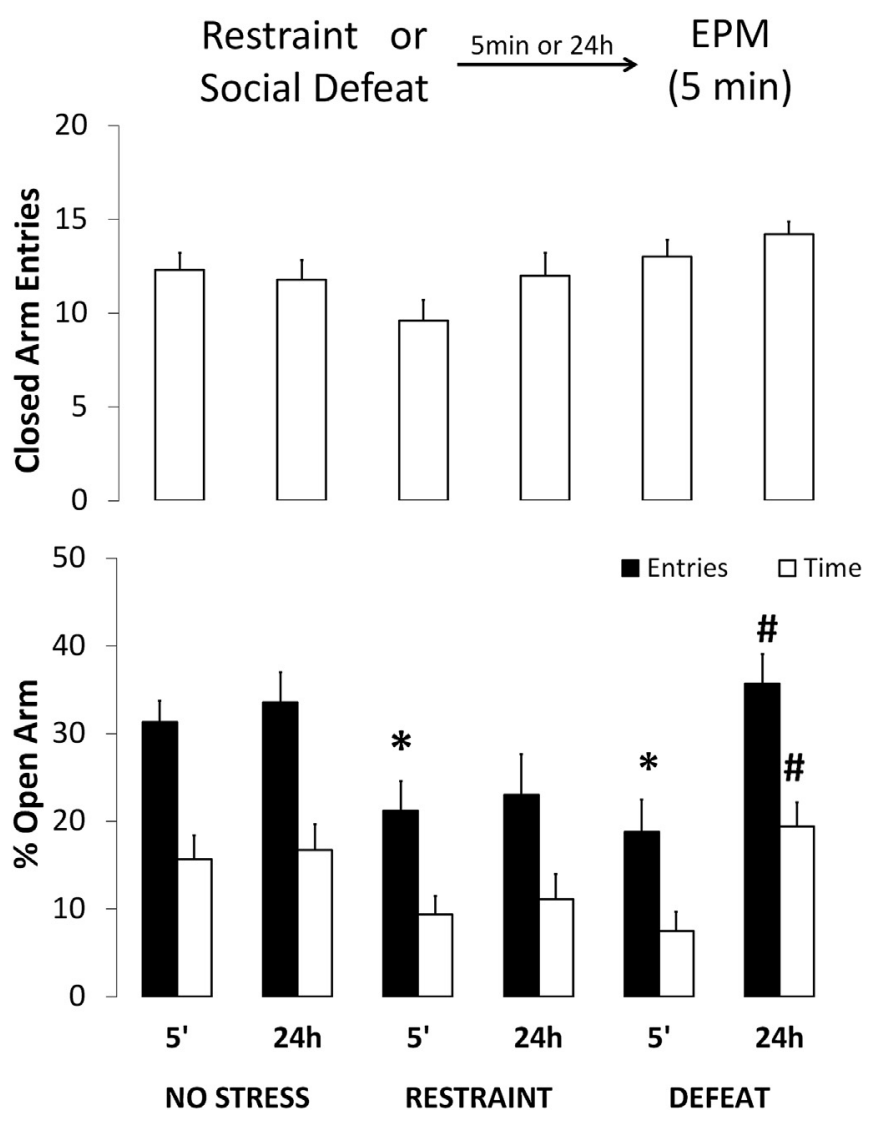

Fig. 4. Anxiogenic-like effects induced by restraint and social defeat in mice exposed to the EPM at $5 \mathrm{~min}$ or $24 \mathrm{~h}$ after stress. Upper panel: Frequency of closed-arm entries; lower panel: percentage of open-arm entries and percentage of open-arm time. $\mathrm{n}=(9-13) ;{ }^{*} \mathrm{p}<0.05$ in comparison to the control group; $\# \mathrm{p}<0.05$ in comparison to the socially defeated group at 5-min.

Importantly, although the \%OE and \%OT exhibited by socially defeated mice did not differ from those of the control group at $24 \mathrm{~h}$ after stress, both variables were higher than those displayed

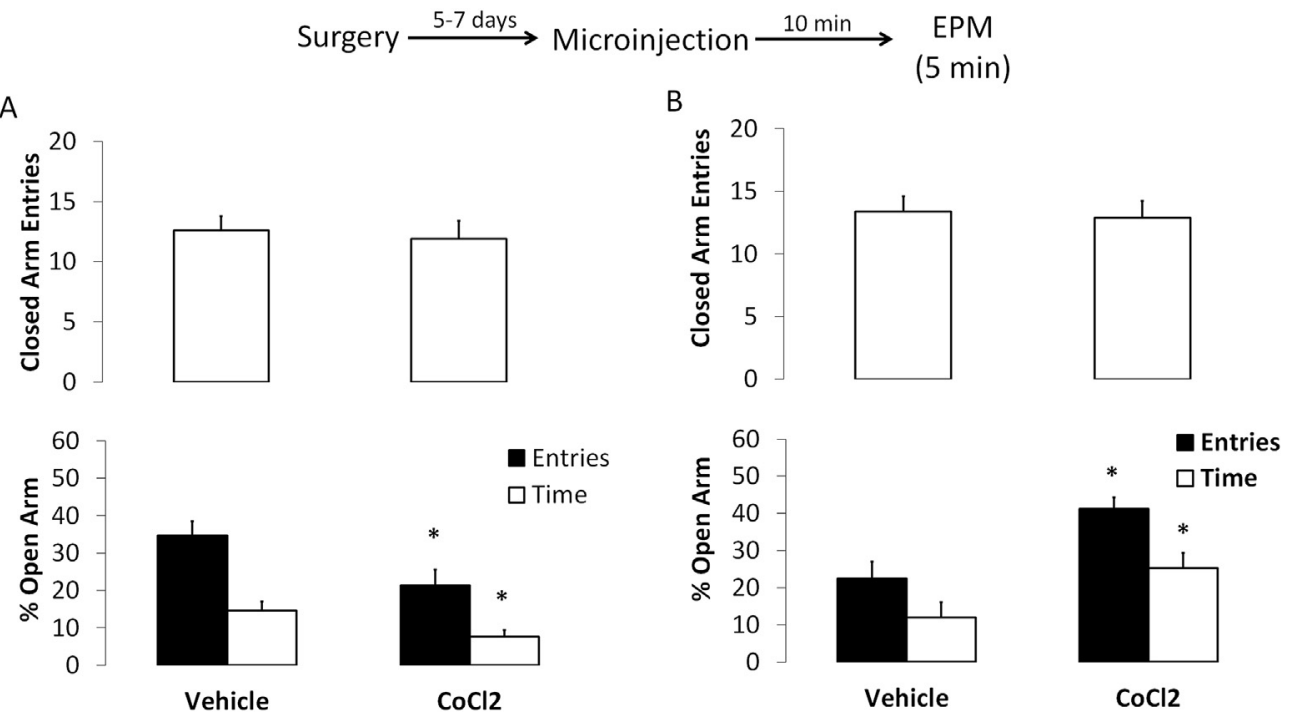

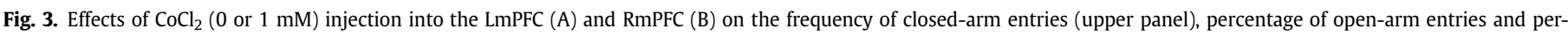
centage of open-arm time (lower panel) in mice exposed to the EPM. * $\mathrm{p}<0.05$ in comparison to the vehicle group. 
by the socially defeated mice at 5 min post-stress. Regarding the closed-arm entries, a two-way ANOVA revealed an effect of only the stress factor [stress $\mathrm{F}(2,62)=3.78 ; \mathrm{p}<0.03)$; time factor $\mathrm{F}(1,62)=1.52 ; \mathrm{p}>0.05$; stress $\times$ time interaction $\mathrm{F}(2,62)=1.11$; $\mathrm{p}>0.05]$. However, post hoc test showed that restraint stress reduced general locomotion $(\mathrm{p}<0.05)$ in comparison to the social defeat group but not the control group.

\subsection{Experiment 4: inhibition of the LmPFC leads to recrudescence of anxiety induced by social defeat (but not by restraint) stress}

Fig. 5 shows the behavior exhibited by mice in the EPM at $24 \mathrm{~h}$ after receiving saline or $\mathrm{CoCl}_{2}$ injections into the $\mathrm{LmPFC}$ and being exposed to restraint or social defeat. Two-way ANOVA did not reveal any effect of treatment $[F(1,61)=1.88 ; p=0.17]$ or of stress $[F(2,61)=1.29 ; p=0.28]$ factors but showed an effect of treatment $\times$ stress interaction $(F(2,61)=3.88 ; p=0.03)$ on the percentage of open-arm entries. A quite similar profile was revealed by a two-way ANOVA for the percentage of open-arm time [treatment factor: $F(1,61)=3.41 ; \mathrm{p}=0.07$; stress factor: $\mathrm{F}(2,61)=1.50 ; \mathrm{p}=0.23$; treatment $\times$ stress interaction: $\mathrm{F}(2,61)=4.23 ; \mathrm{p}=0.02]$. Post hoc Duncan's test showed that intraLmPFC injection of $\mathrm{CoCl}_{2}$ reduced both \%OE and \%OT but only for socially defeated mice compared to all groups (\%OE: $\mathrm{p} \leq 0.04$; \%OT: $\mathrm{p} \leq 0.02$ ). Regarding the frequency of closed-arm entries, a twoway ANOVA revealed a significant effect of stress factor $[F(2,61)=3.87 ; \mathrm{p}=0.03]$ but not of treatment factor $[\mathrm{F}(1,61)=1.89 ; \mathrm{p}=0.17]$ or of the treatment $\times$ stress interaction $[F(2,61)=1.08 ; p=0.34]$. Post hoc comparisons revealed that defeated mice showed a lower frequency of closed-arm entries than non-stressed and restrained animals $(\mathrm{p}<0.05)$.

\section{Discussion}

The main results of the present study showed that although nitrergic activation of the right MPFC produces robust anxiogeniclike effects, bilateral or unilateral (into the left mPFC) injections of NOC-9, an NO donor, do not change the anxiety of mice exposed to the EPM, thereby suggesting that nitrergic production in the left mPFC somehow inhibits the anxiogenic-like effect induced by NO in the right $\mathrm{mPFC}$. Interestingly, while chemical inhibition of the right $\mathrm{MPFC}$, through the local injection of $\mathrm{CoCl}_{2}$, attenuated the anxiety indices in the EPM, injection of this synaptic inhibitor into the left $\mathrm{mPFC}$ produced anxiogenesis, thereby suggesting that the right $\mathrm{MPFC}$ and left $\mathrm{MPFC}$ have distinct roles in the modulation of the basal levels of anxiety in mice. Moreover, the left mPFC seems to be important in modulating some types of stress-induced anxiety because its temporary inactivation, in combination with the exposure to social defeat, resulted in anxiety recrudescence in mice.

Nitrergic activation of the RmPFC produced a dose-related and selective anxiogenic-like effect in mice exposed to the EPM. Evidence that NOC-9 produces anxiogenic effects in mice exposed to the EPM were previously shown through local injections of this NO donor into the midbrain periaqueductal gray (PAG) and bed nucleus of the stria terminalis (BNST) (e.g., Braga et al., 2009; Miguel et al., 2012; Faria et al., 2016). However, intra-PAG injections of NOC-9 elicited explosive motor behaviors (e.g., jumping and running) followed by freezing (Miguel et al., 2012), whereas infusion of this NO donor into the BNST produced only freezing (i.e., no jumps and running) followed by anxiety-related behaviors in mice exposed to the EPM (Faria et al., 2016). Although we did not record systematic jumping, running or freezing behavior in the present study,
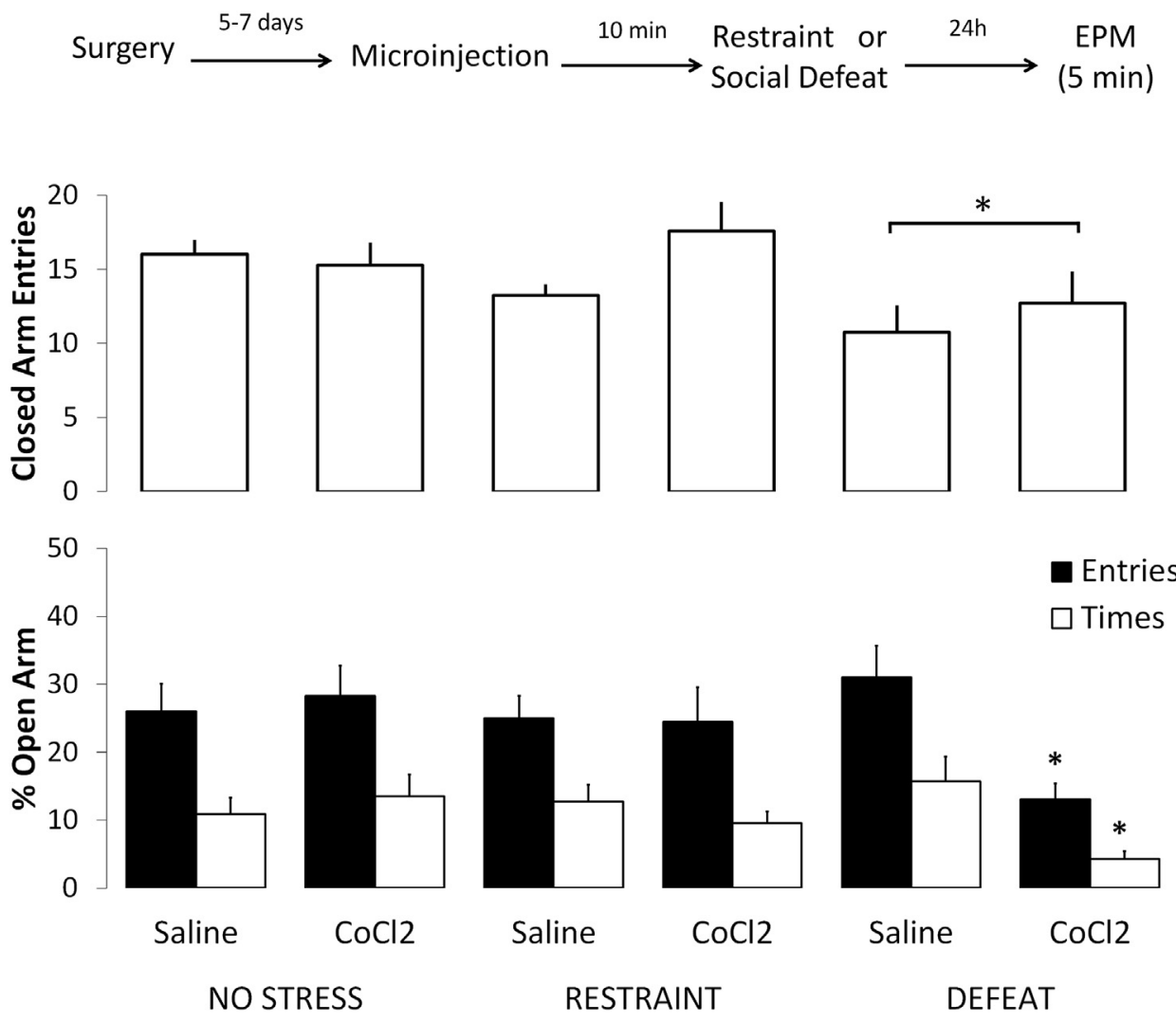

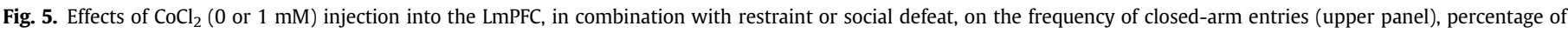
open-arm entries and percentage of open-arm time (lower panel) in mice exposed to the EPM at $24 \mathrm{~h}$ after stress. $\mathrm{n}=7-14$ per group. * $<<0.05$ in comparison to all groups. 
experimenters did not observe such sudden and intense behavioral responses following intra-mPFC injections of the NO donor. However, robust anxiogenic-like effects of intra-RmPFC NOC-9 were recorded in mice exposed to the EPM. An aversive role of NO in the prefrontal cortex has been previously noted in studies showing that local injections of Nw-propyl-L-arginine, an NO synthase inhibitor (Zhang et al., 1997), or carboxi-PTIO, an NO scavenger (e.g., Pfeiffer et al., 1997), impair avoidance acquisition in the Vogel conflict test (Lisboa et al., 2010) and contextual fear conditioning (Resstel et al., 2008), respectively. Together, the present results corroborate previous evidence that indicates that anxiety and fear behaviors are coordinated by a hierarchical brain defensive system (McNaughton and Corr, 2004). These authors have argued that although the anxiety state is mediated mainly by forebrain structures (e.g., prefrontal dorsal stream, posterior cingulate, septo-hipocampal system and amygdala), the fear state involves more caudal structures (e.g., medial hypothalamus and periaqueductal gray). Although it would be expected that both rostral and caudal limbic structures play a role in the modulation of anxiety and fear, the mPFC seems to be a forebrain area involved in the modulation of more subtle defensive behaviors.

Regarding the mechanisms by which NO produces anxiogeniclike effects in the MPFC, the neurotransmissions mediated by the excitatory amino acid glutamate and/or the neuropeptide corticotrophin releasing factor (CRF) seem to be strong candidates. In this context, previous studies have suggested that NO production results in the release of glutamate in the PAG (Moreira et al., 2004) and CRF in the amygdala and hypothalamus (Raber et al., 1995). In addition, intra-mPFC injections of L-NOARG, a non-selective NO synthase inhibitor, decreased the release of glutamate induced by glutamate NMDA receptor activation in cells of the cerebral cortex (Montague et al., 1994), thereby suggesting that the glutamatergic action on this limbic structure is NO-dependent. Regarding CRF neurotransmission, Miguel et al. (2014) have recently demonstrated that intra-mPFC injection of the neuropeptide CRF and the selective CRF1 receptor antagonist, CP376395, increased and attenuated, respectively, anxiety-related behaviors of mice exposed to the EPM. Moreover, there is evidence that indicates that the anxiogenic effects of NOC-9 are blocked with prior injection of CRF1 antagonists in the mouse PAG (Miguel et al., 2012) and BNST (Faria et al., 2016). In addition, intra-BNST injection of AP-7, a glutamate NMDA receptor antagonist, also blocked the anxiogenic effects of local infusions of NOC-9 (Faria et al., 2016), thereby suggesting that NO production could be increasing CRF and glutamate release within these brain areas. However, it is notable that NO interferes with the release of other neurotransmitters (e.g., acetylcholine, dopamine, serotonin and GABA) that are potential candidates for modulating anxiety (de Oliveira et al., 2000; Moreira and Guimarães, 2004; Moreira et al., 2004).

An impressive result of the present study is the lack of effects on anxiety of injection of NOC-9 into either the bilateral or left mPFC. Given that intra-RmPFC NOC-9 increases anxiety, the lack of effects on anxiety after bilateral nitrergic activation suggests that NO release within the LmPFC somehow impairs the anxiogenic-like effect produced by NO in the RmPFC. However, as shown in the present study (Fig. 2C), intra-LmPFC injections of NOC-9 failed to alter anxiety indices. In other words, these results suggest that NO production in the MPFC localized to the left hemisphere does not produce anxiolytic-like effects. Together, these results are suggestive that nitrergic activation in the LmPFC could facilitate the coping of mice with aversive situations that are NO-dependent in the RmPFC. If so, inhibition of the LmPFC would impair the ability of animals to cope with threatening situations.

In this context, Experiment 2 revealed that chemical inactivation of the LmPFC through the local injection of $\mathrm{CoCl}_{2}$, an unspecific synaptic inhibitor (Kretz, 1984), produced anxiogenic-like effects (i.e., mice reduced their exploration of the open arms of the EPM). In contrast, when injected into the RmPFC, $\mathrm{CoCl}_{2}$ attenuated both indices of anxiety (\%OE and \%OT; i.e., mice increased their exploration of the potentially aversive area of the EPM). Importantly, inhibition of the RmPFC or of the LmPFC did not change the general activity because the frequency of closed-arm entries remained unaltered in both cases. Furthermore, the anxiogenic-like effects induced by intra-LmPFC injection of $\mathrm{CoCl}_{2}$ are quite similar to those observed with intra-RmPFC injection of NOC-9 (Fig. 2A). Together, the results of Experiments 1 and 2 are suggestive that the MPFC has a lateralized function in the control of anxiety of mice confronting threatening situations. Although the RmPFC would normally be integrated into active, pro-aversive behavioral action (i.e., its nitrergic activation results in mice avoiding or escaping from the open arms), the LmPFC attenuates the behavioral consequences triggered by a potentially aversive situation, which were represented, in the present study, by the open arms of the EPM.

Several studies have highlighted the effects of various stressors on brain functioning, thereby indicating that some brain areas are particularly affected by acute and chronic stress (e.g., Gee and Casey, 2015). In this context, the mPFC is closely related to the preparation of emotional responses to stress (Vermetten and Bremner, 2002; Gold et al., 2015; Maren and Holmes, 2015). Based on this evidence and the results of Experiments 1 and 2 of the present study, we investigated whether the inhibition of LmPFC could modulate the effect of two types of stress (the restraint and the social defeat) on anxiety. To that end, we first investigated the effects of these two stressors on anxiety-like behavior in control mice exposed to the EPM at 5 min or $24 \mathrm{~h}$ after stress. Thus, both stressors elicited acute anxiogenic-like behavior, which resulted in decreased open-arm exploration of mice exposed to the EPM at 5 min after stress. However, the effects of restraint and social defeat on anxiety in mice exposed to the EPM 24 h later were not clear. Actually, although restraint produced a weak anxiogenic effect (i.e., it reduced only \%OE), social defeat did not change anxiety indices $24 \mathrm{~h}$ post-stress, thereby suggesting that these two types of stressors do not provoke long-lasting anxiogenic-like effects. Namely, at $24 \mathrm{~h}$ after exposure to stress, animals display resilience to the anxiogenic effects induced, in particular, by social defeat.

In Experiment 4, we investigated whether the LmPFC would play a role in the ability of animals to cope with the aversive effects of stress. As shown in Fig. 5, the inhibition of LmPFC followed by social defeat stress resulted in anxiogenic-like effects in mice exposed to EPM $24 \mathrm{~h}$ later. Social defeat stress also led to a reduction in general locomotion, as represented by lower frequencies of closed-arm entries, an effect that did not depend upon drug injection. Together these results strongly suggest that the anxiogenic-like effects induced by social defeat depend upon the chemical inhibition of the LmPFC. Interestingly, intra-LmPFC injection of $\mathrm{CoCl}_{2}$ did not change anxiety indices in non-stressed or restrained animals. The lack of effects observed with LmPFC inhibition on the anxiety of nonstressed animals was an expected result, particularly if (i) the inhibitory effect of this synaptic blocker persists for approximately 30-60 min (Lomber, 1999) and (ii) the test on the EPM was conducted only $24 \mathrm{~h}$ after LmPFC inhibition. Conversely, we do not have a clear explanation for the lack of effects of the combined intraLmPFC $\mathrm{CoCl}_{2}$ injection and restraint stress on anxiety in mice exposed to the EPM. A speculative explanation of these intriguing results is reflected in the recent study by Motta and Canteras (2015), which demonstrated that the pattern of neuronal activation may be different for animals that were immobilized (restrained) than for those that experienced social defeat. Although this study described that immobilization and social defeat show commonalities in neuronal Fos activation in regions of the hypothalamic circuit of 
defense, the study also found that socially defeated rats, but not restrained rats, recruited elements of the medial hypothalamic conspecific-responsive circuit, which is also involved in other forms of social interaction (Canteras, 2012). Thus, the ability of the restraint stress to induce distinct neuronal mechanisms in the mPFC in comparison to those induced by social defeat in mice requires further investigation. Therefore, it seems imperative that the functional lateralization of this limbic structure must be considered.

Sullivan and Gratton (1999) emphasized that the mPFC has a lateralized function in the modulation of stress-induced responses in rats. According to them, the RmPFC plays a role in the modulation of physiological responses induced by stress. Moreover, Cerqueira et al. (2008) postulated that although the LmPFC coordinates motor functions, the RmPFC modulates affective and emotional responses to repeated stress. In addition, according to Czéh et al. (2008), the mPFC has an intrinsic cellular asymmetry, and the LmPFC exerts a dominant role in the control of stress responses in rats. Additionally, Sullivan and Gratton (2002) suggested that the LmPFC is more involved in the regulation of immediate stress control, thereby optimizing cautions and adaptive behavior in potentially threatening situations. If so, the present results seem to corroborate these observations, which show that nitrergic activation of the RmPFC, but not of both the LmPCF and RMPCF, is anxiogenic. Moreover, in basal levels of anxiety (e.g., during an exposure to the EPM), nitrergic activation of the LmPFC seems to control the emotional response elicited by the potentially threatening situation as it neither attenuated nor intensified the avoidance of the open arms. However, inhibition of the LmPFC appears to mimic the behavioral effects of chronic stress, which leads to dendritic atrophy (Cerqueira et al., 2008), thereby causing an enhancement of anxiety indices in the EPM, as shown in the present study (Fig. 3A).

Several studies have highlighted the role of the PFC as a key structure involved in resilience and vulnerability to stress (McEwen and Morrison, 2013; Van den Hove et al., 2013). For instance, Maier and Watkins (2010) suggested that mPFC activation is crucial for detecting environmental clues and for enabling behavioral control, which, in turn, modulates vulnerability and resistance/resilience to aversive situations. Although these findings have not been localized in a particular hemisphere (i.e., right versus left), the present results following LmPFC inhibition seem to be consistent with the study of Maier and Watkins. Thus, synaptic inhibition of the LmPFC immediately before social defeat stress resulted in the recrudescence of anxiety-like behavior when recorded $24 \mathrm{~h}$ later. Notably, no anxiety-related behavior was observed $24 \mathrm{~h}$ after the social conflict in LmPFC-intact mice or in non-stressed mice that had received intra-LmPFC injection of $\mathrm{CoCl}_{2}$ one day earlier.

\section{Conclusion}

The present study demonstrates that the MPFC has a lateralized function in the modulation of anxiety of mice exposed to the EPM. NO neurotransmission located within the MPFC, particularly in its right hemisphere, has a notable role in this process. In addition, although this brain structure is located in the right hemisphere and appears to exert a tonic role in the control of anxiety-like responses, the left side appears to modulate the aversiveness of a given environmental context (e.g., the EPM). Moreover, the functional integrity of the LmPFC also contributes to the ability of mice to cope with the anxiogenic effects induced by social defeat.

\section{Acknowledgements}

We thank Elisabete Z.P. Lepera and Rosana F.P. Silva for their technical assistance. This study was supported by FAPESP (2013/
01383-6), CNPq (478696/2013-2) and CAPES (2053/2013). N.S. Costa, A.C. Cipriano, T.T. Miguel and M.A. Vicente received, respectively, CNPq (161440/2014-2), FAPESP (2011/04561-1), CAPES-PNPD (2748/2010) and CAPES-PNPD (2053/2013) scholarships, and R. L. Nunes-de-Souza a CNPq (305597/2012-4) fellowship.

\section{References}

Ambalavanan, N., Mariani, G., Bulger, A., Philips III, J.B., 1999. Role of nitric oxide in regulating neonatal porcine pulmonary artery smooth muscle cell proliferation. Biol. Neonate 76 (5), 291-300.

Bechara, A., Damasio, H., 2002. Decision-making and addiction (part I): impaired activation of somatic states in substance dependent individuals when pondering decisions with negative future consequences. Neuropsychologia 40 (10), 1675-1689.

Braga, A.A., Aguiar, D.C., Guimarães, F.S., 2009. NOC-9, a selective nitric oxide donor, induces flight reactions in the dorsolateral periaqueductal gray of rats by activating soluble guanylate cyclase. Neurosci. Lett. 459 (2), 79-83.

Canteras, N.S., 2012. Hypothalamic goal-directed behavior - ingestive, reproductive and defensive. In: Watson, C., Paxinos, G., Puelles, L. (Eds.), The Mouse Nervous System. Academic Press, Sidney, pp. 539-562.

Carobrez, A.P., Teixeira, K.V., Graeff, F.G., 2001. Modulation of defensive behavior by periaqueductal gray NMDA/glycine-B receptor. Neurosci. Biobehav Rev. 25 (7-8), 697-709.

Cerqueira, J.J., Almeida, O.F., Sousa, N., 2008. The stressed prefrontal cortex. Left? Right! Brain Behav. Immun. 22 (5), 630-638.

Cerqueira, J.J., Mailliet, F., Almeida, O.F., Jay, T.M., Sousa, N., 2007. The prefrontal cortex as a key target of the maladaptive response to stress. J. Neurosci. 27 (11), 2781-2787.

Courtin, J., Bienvenu, T.C., Einarsson EÖ, Herry C., 2013. Medial prefrontal cortex neuronal circuits in fear behavior. Neuroscience 240, 219-242.

Crestani, C.C., Alves, F.H., Correa, F.M., Guimarães, F.S., Joca, S.R., 2010. Acute reversible inactivation of the bed nucleus of stria terminalis induces antidepressant-like effect in the rat forced swimming test. Behav. Brain Funct. 1 (6), 30.

Crestani, C.C., Alves, F.H., Tavares, R.F., Corrêa, F.M., 2009. Role of the bed nucleus of the stria terminalis in the cardiovascular responses to acute restraint stress in rats. Stress 12 (3), 268-278.

Czéh, B., Perez-Cruz, C., Fuchs, E., Flügge, G., 2008. Chronic stress-induced cellular changes in the medial prefrontal cortex and their potential clinical implications: does hemisphere location matter? Behav. Brain Res. 190 (1), 1-13.

Ariëns Kappers Lecture Damasio, A.R., Eighth, C.U., 2000. The fabric of the mind: a neurobiological perspective. Prog. Brain Res. 126, 457-467.

Davidson, R.J., 1998. Cerebral asymmetry, emotions and affective style. In: Davidson, R.J., Hughdahl, K. (Eds.), Brain Asymmetry. MIT Press, Cambridge, pp. $361-387$.

de Oliveira, R.M., Del Bel, E.A., Mamede-Rosa, M.L., Padovan, C.M., Deakin, J.F. Guimaraes, F.S., 2000. Expression of neuronal nitric oxide synthase mRNA in stress-related brain areas after restraint in rats. Neurosci. Lett. 289, 123-126.

Del Carlo Jr., M., Loeser, R.F., 2002. Nitric oxide-mediated chondrocyte cell death requires the generation of additional reactive oxygen species. Arthritis Rheum. 46 (2), 394-403.

Euston, D.R., Gruber, A.J., McNaughton, B.L., 2012. The role of medial prefrontal cortex in memory and decision making. Neuron 76 (6), 1057-1070.

Faria, M.P., Miguel, T.T., Gomes, K.S., Nunes-de-Souza, R.L., 2016. Anxiety-like responses induced by nitric oxide within the BNST in mice: role of CRF1 and NMDA receptors. Hormon. Behav. 79, 74-83.

Fogaça, M.V., Aguiar, D.C., Moreira, F.A., Guimarães, F.S., 2012. The endocannabinoid and endovanilloid systems interact in the rat prelimbic medial prefrontal cortex to control anxiety-like behavior. Neuropharmacology 63 (2), 202-210.

Gee, D.G., Casey, B.J., 2015. The impact of developmental timing for stress and recovery. Neurobiol. Stress 1, 184-194.

Gold, A.L., Morey, R.A., McCarthy, G., 2015. Amygdala-prefrontal cortex functional connectivity during threat-induced anxiety and goal distraction. Biol. Psychiatry $77(4), 394-403$.

Gonzalez, L.E., Rujano, M., Tucci, S., Paredes, D., Silva, E., Alba, G., Hernandez, L., 2000. Medial prefrontal transection enhances social interaction. I: behavioral studies. Brain Res. 887 (1), 7-15.

Gruber, A.J., Calhoon, G.G., Shusterman, I., Schoenbaum, G., Roesch, M.R., O'Donnell, P., 2010. More is less: a disinhibited prefrontal cortex impairs cognitive flexibility. J. Neurosci. 30 (50), 17102-17110.

Guimarães, F.S., Beijamini, V., Moreira, F.A., Aguiar, D.C., de Lucca, A.C., 2005. Role of nitric oxide in brain regions related to defensive reactions. Neurosci. Biobehav. Rev. 29 (8), 1313-1322.

Holmes, A., Wellman, C.L., 2009. Stress-induced prefrontal reorganization and executive dysfunction in rodents. Neurosci. Biobehav. Rev. 33 (6), 773-783.

Jaferi, A., Bhatnagar, S., 2007. Corticotropin-releasing hormone receptors in the medial prefrontal cortex regulate hypothalamic-pituitary-adrenal activity and anxiety-related behavior regardless of prior stress experience. Brain Res. 1186, 212-223.

Johnstone, T., van Reekum, C.M., Urry, H.L., Kalin, N.H., Davidson, R.J., 2007. Failure 
to regulate: counterproductive recruitment of top-down prefrontal-subcortical circuitry in major depression. J. Neurosci. 27 (33), 8877-8884.

Kretz, R., 1984. Local cobalt injection: a method to discriminate presynaptic axonal from postsynaptic neuronal activity. J. Neurosci. Methods 11 (2), 129-135.

Lacroix, L., Spinelli, S., Heidbreder, C.A., Feldon, J., 2000. Differential role of the medial and lateral prefrontal cortices in fear and anxiety. Behav. Neurosci. 114 (6), 1119-1130.

Lisboa, S.F., Stecchini, M.F., Corrêa, F.M., Guimarães, F.S., Resstel, L.B., 2010. Different role of the ventral medial prefrontal cortex on modulation of innate and associative learned fear. Neuroscience 171 (3), 760-768.

Lohse, M.J., Förstermann, U., Schmidt, H.H., 1998. Pharmacology of NO:cGMP signal transduction. Naunyn Schmiedeb. Arch. Pharmacol. 358 (1), 111-112.

Lomber, S.G., 1999. The advantages and limitations of permanent or reversible deactivation techniques in the assessment of neural function. J. Neurosci. Methods 86 (2), 109-117. Review.

Maier, S.F., Watkins, L.R., 2010. Role of the medial prefrontal cortex in coping and resilience. Brain Res. 1355, 52-60.

Maren, S., Holmes, A., 2016. Stress and fear extinction. Neuropsychopharmacology 41 (1), 58-79. http://dx.doi.org/10.1038/npp.2015.180.

Mayer, B., John, M., Heinzel, B., Werner, E.R., Wachter, H., Schultz, G., Bohme, E., 1991. Brain nitric oxide synthase is a biopterin- and flavin-containing multifunctional oxido-reductase. FEBS Lett. 288, 187-191.

McEwen, B.S., Morrison, J.H., 2013. The brain on stress: vulnerability and plasticity of the prefrontal cortex over the life course. Neuron 79 (1), 16-29. Review.

McNaughton, N., Corr, P.J., 2004. A two-dimensional neuropsychology of defense: fear/anxiety and defensive distance. Neurosci. Biobehav Rev. 28 (3), 285-305. Review.

Miguel, T.T., Gomes, K.S., Nunes-de-Souza, R.L., 2012. Contrasting effects of nitric oxide and corticotropin- releasing factor within the dorsal periaqueductal gray on defensive behavior and nociception in mice. Braz J. Med. Biol. Res. 45 (4), 299-307.

Miguel, T.T., Gomes, K.S., Nunes-de-Souza, R.L., 2014. Tonic modulation of anxietylike behavior by corticotropin-releasing factor (CRF) type 1 receptor (CRF1) within the medial prefrontal cortex ( $\mathrm{MPFC}$ ) in male mice: role of protein kinase A (PKA). Horm. Behav. 66 (2), 247-256.

Molchanov, M.L., Guimarães, F.S., 2002. Anxiolytic-like effects of AP7 injected into the dorsolateral or ventrolateral columns of the periaqueductal gray of rats. Psychopharmacol. Berl. 160 (1), 30-38.

Montague, P.R., Gancayco, C.D., Winn, M.J., Marchase, R.B., Friedlander, M.J., 1994. Role of NO production in NMDA receptor-mediated neurotransmitter release in cerebral cortex. Science 263 (5149), 973-977.

Moreira, F.A., Guimarães, F.S., 2004. Benzodiazepine receptor and serotonin 2A receptor modulate the aversive-like effects of nitric oxide in the dorsolateral periaqueductal gray of rats. Psychopharmacol. Berl. 176 (3-4), 362-368.

Moreira, F.A., Molchanov, M.L., Guimarães, F.S., 2004. Ionotropic glutamate-receptor antagonists inhibit the aversive effects of nitric oxide donor injected into the dorsolateral periaqueductal gray of rats. Psychopharmacol. Berl. 171 (2), 199-203.

Morot Gaudry-Talarmain, Y., Moulian, N., Meunier, F.A., Blanchard, B., AngautPetit, D., Faille, L., Ducrocq, C., 1997. Nitric oxide and peroxynitrite affect differently acetylcholine release, choline acetyltransferase activity, synthesis, and compartmentation of newly formed acetylcholine in Torpedo marmorata synaptosomes. Nitric Oxide 1 (4), 330-345.

Motta, S.C., Canteras, N.S., 2015. Restraint stress and social defeat: what they have in common. Physiol. Behav. 146, 105-110.
Miczek, K.A., Thompson, M.L., Shuster, L., 1982. Opioid-like analgesia in defeated mice. Science 215 (4539), 1520-1522.

Paxinos, G., Franklin, K.B.J., 2001. The Mouse Brain in Stereotaxic Coordinates. Academic Press, California, USA.

Pfeiffer, S., Leopold, E., Hemmens, B., Schmidt, K., Werner, E.R., Mayer, B., 1997 Interference of carboxy-PTIO with nitric oxide- and peroxynitrite-mediated reactions. Free Radic. Biol. Med. 22 (5), 787-794.

Raber, J., Koob, G.F., Bloom, F.E., 1995. Interleukin-2 (IL-2) induces corticotropinreleasing factor (CRF) release from the amygdala and involves a nitric oxidemediated signaling; comparison with the hypothalamic response. J. Pharmacol. Exp. Ther. 272 (2), 815-824.

Resstel, L.B., Corrêa, F.M., Guimarães, F.S., 2008. The expression of contextual fear conditioning involves activation of an NMDA receptor-nitric oxide pathway in the medial prefrontal cortex. Cereb. Cortex 18 (9), 2027-2035.

Resstel, L.B., Fernandes, K.B., Corrêa, F.M., 2004. Medial prefrontal cortex modulation of the baroreflex parasympathetic component in the rat. Brain Res. 1015 $(1-2), 136-144$.

Rodgers, R.J., Johnson, N.J., 1995. Factor analysis of spatiotemporal and ethological measures in the murine elevated plus-maze test of anxiety. Pharmacol. Biochem. Behav. 52 (2), 297-303.

Scopinho, A.A., Scopinho, M., Lisboa, S.F., Correa, F.M., Guimarães, F.S., Joca, S.R. 2010. Acute reversible inactivation of the ventral medial prefrontal cortex induces antidepressant-like effects in rats. Behav, Brain Res. 214 (2), 437-442.

Seccia, M., Perugini, C., Albano, E., Bellomo, G., 1996. Inhibition of Cu2+-induced LDL oxidation by nitric oxide: a study using donors with different half-time of NO release. Biochem. Biophys. Res. Commun. 220 (2), 306-309.

Shah, A.A., Treite, D., 2003. Excitotoxic lesions of the medial pfc attenuate fear responses in the epm, social interaction and shock probe burying tests. Brain Res. 969, 183-194.

Sullivan, R.M., Gratton, A., 1999. Lateralized effects of medial prefrontal cortex lesions on neuroendocrine and autonomic stress responses in rats. J. Neurosci. 19 (7), 2834-2840.

Sullivan, R.M., Gratton, A., 2002. Behavioral effects of excitotoxic lesions of ventral medial prefrontal cortex in the rat are hemisphere-dependent. Brain Res. 927 (1), 69-79.

Tavares, R.F., Corrêa, F.M., 2006. Role of the medial prefrontal cortex in cardiovascular responses to acute restraint in rats. Neuroscience 143 (1), 231-240.

Van den Hove, D.L., Kenis, G., Brass, A., Opstelten, R., Rutten, B.P., Bruschettini, M. Blanco, C.E., Lesch, K.P., Steinbusch, H.W., Prickaerts, J., 2013. Vulnerability versus resilience to prenatal stress in male and female rats; implications from gene expression profiles in the hippocampus and frontal cortex. Eur. Neuropsychopharmacol. 23 (10), 1226-1246.

Vermetten, E., Bremner, J.D., 2002. Circuits and systems in stress. II. Applications to neurobiology and treatment in posttraumatic stress disorder. Depress Anxiety 16 (1), 14-38. Review.

Vianna, D.M., Graeff, F.G., Landeira-Fernandez, J., Brandao, M.L., 2001. Lesion of the ventral periaqueductal gray reduces conditioned fear but does not change freezing induced by stimulation of the dorsal periaqueductal gray. Learn Mem. 8, 164-169.

Yuan, P., Raz, N., 2014. Prefrontal cortex and executive functions in healthy adults: a meta-analysis of structural neuroimaging studies. Neurosci. Biobehav. Rev. 42 180-192. Review.

Zhang, H.Q., Fast, W., Marletta, M.A., Martasek, P., Silverman, R.B., 1997. Potent and selective inhibition of neuronal nitric oxide synthase by $\mathrm{N}$ omega-propyl-Larginine. J. Med. Chem. 40 (24), 3869-3870. 